\title{
The Effect of PVAc Solution Viscosity on Diameter of PVAc Nanofibres Prepared by Technology of Electrospinning
}

\author{
David Petras $^{\mathrm{a}, \mathrm{b}}$, Petr Slobodian ${ }^{\mathrm{a}}$, Vladimír Pavlínek ${ }^{\mathrm{a}}$, Petr Sáha ${ }^{\mathrm{a}}$ and \\ Dušan Kimmer ${ }^{\mathrm{b}}$
}

${ }^{a}$ Centre of Polymer Systems, Polymer Centre, Tomas Bata University in Zlin, nam. T. G. Masaryka 5555, 76001 Zlin, Czech Republic

${ }^{b}$ SPUR a.s., Tr. Tomase Bati 299, 76302 Zlín, Czech Republic

\begin{abstract}
Polyvinyl acetate (PVAc) nanofibers were prepared by technology of electrospinning with help of multi-jets electrospinning machine from acetic acid/water solvent system. The stability of the process was tested in a broad concentration region from 5 to $40 \mathrm{wt}$. \% of PVAc. The main attention was carried out to study the effect of polyvinyl acetate solution concentration/viscosity onto mean diameter of prepared nanofibers. It was found that increased solution viscosity leads to increase of fibers diameters from appox. $60 \mathrm{~nm}$ at viscosity $\sim 0.04$ Pa.s to appox. $1000 \mathrm{~nm}$ at viscosity 6-7 Pa.s. The PVAc nanofibres can be considered as a potential precursor for preparation of inorganic fibrous nanoparticles. Their dimensions can be effectively controlled by PVAc nanofibers diameter by easy diameter - concentration/viscosity optimalization.
\end{abstract}

Keywords: Polyvinyl acetate, PVAc, Nanofibers, Nanofiber layer, Electrospinning, Acetic acid, Water.

PACS: 83.85.Jn, 81.07.-b, 81.16.-c, 83.60.-a, 83.80.Rs, 61.46.-w, 62.23.-c

\section{INTRODUCTION}

Polyvinyl acetate (PVAc) is often used as a carrier polymer for preparation of inorganic nanofibers. Such inorganic nanofibers are not prepared directly, but through organic nanofiber precursor. The precursor nanofibers are usually fabricated by technology of electrospinning from PVAc solution together with appropriate well thermally decomposable metal salt. This precursor is then calcined when inorganic nanofiber or nanowhiskers are formed [1,2]. Nanomaterials made of pure metals or their oxides are prepared according condition of calcination. This new inorganic materials are promising for application in area of semiconductors $[3,4]$.

The technology of electrospinning is one of the most used methods to prepare ultra-thin fibers [5-9]. PVAc solutions are usually used for their production. But commonly used solvents like dimethylformamide, ketones or alcohols $[1,2,5]$ are not 
fully environmentally acceptable because of their toxicity. Another technological disadvantage is in their flammability. The solvent system based on the mixture of acetic acid and water can significantly eliminate these problems. Finally, the reduction of the amount of acetic acid in favour of water is also advantageous form economical aspects.

The structure of the prepared nanofiber precursors (polymer and metal salts) always affects the parameters of the resulting inorganic nanofibers [10]. The PVAc nanofibers diameter seems to be a basic parameter which would be controlled from this point of view. It is known that the fiber diameter is influenced by numerous parameters during electrospinning. But the basic parameter is polymer solution concentration. More concentrated solutions have higher solution viscosity, the increase in viscosity leads to thicker fibers $[6,11,12]$.

The aim of this work is to test new solvent system for electrospinning of PVAc solutions based on the mixture of acetic acid with water. This system is non-toxic, non-flammable and low-cost. Further, the broad range of concentration/viscosities is tested to find when nanofibers are formed by technology of electrospinning. Finally, the analysis of effect of solution viscosity onto nanofibers diamether is performed.

\section{EXPERIMENTAL AND RESULTS}

Materials: PVAc (Mcgean, Polyvinylacetate beads B-15, $\mathrm{M}_{\mathrm{w}} 90,000 \mathrm{~g} \cdot \mathrm{mol}^{-1}$ ), acetic acid (Penta Chemikalie, Czech republic, p.a.) and demineralized water (electrical conductivity $0.40 \mu \mathrm{S} / \mathrm{cm})$.

Process: Three different PVAc concentrations series were prepared, one in pure acetic acid (AA) and two in mixture of acetic acid with water $\left(\mathrm{AA}: \mathrm{H}_{2} \mathrm{O}\right)$ in concentration ratios $3: 1$ and $1: 1(\mathrm{v} / \mathrm{v})$ from 5 to $40 \mathrm{wt}$. \% of dissolved PVAc. There was attempt to prepare also solutions in volume ratio 1:3 but PVAc does not dissolve. Concentration step was $1 \mathrm{wt}$. $\%$ for concentration range from 5 to $10 \mathrm{wt}$. \% and $2.5 \mathrm{wt}$. $\%$ from 10 to $40 \mathrm{wt} \%$. Homogeneous and clear solutions were prepared by mechanical stirring at $160 \mathrm{rpm}$ for $4 \mathrm{~h}$ at room temperature $\left(22^{\circ} \mathrm{C}\right)$. Non-woven layers of PVAc nanofibers were prepared by technology of electrospinning from solutions using laboratory multi-jet apparatus (SPUR a.s., Czech republic), see schematic illustration, Figure 1. The main processing parameters were: solution flow rate $0.4 \mathrm{ml} / \mathrm{min}$, high voltage electrospinning electrode (multi-jest head) $+80 \mathrm{kV} \quad \mathrm{DC}$, electrode distance $180 \mathrm{~mm}$, processing temperature: $20 \pm 2{ }^{\circ} \mathrm{C}$ and processing relative humidity $30.0 \pm 2.5 \%$. Aluminum foil (thickness: $0.5 \mathrm{~mm}$, dimension: 300 x $300 \mathrm{~mm}$ ) was used as collecting substrate. The duration of continuous process was about $120 \mathrm{~s}$.

Analyses: The structure of fibers was observed by a scanning electron microscope (SEM) Vega LMU made by Tescan s.r.o., Czech Republic. The network was deposited on the carbon targets and covered with a thin $\mathrm{Au} / \mathrm{Pd}$ layer. For the observations the regime of 
secondary electrons was chosen. The fiber diameter was determined by analyzing of SEM images, $\mathrm{n} \sim 100$. Rheological properties of all solutions were determined under controlled shear rate mode using rotational viscometer (Bohlin Gemini, Malvern Instruments, UK) in concentric cylinder geometry in the shear rate range $0.6-60 \mathrm{~s}^{-1}$. Rotating inner cylinder of $14 \mathrm{~mm}$ diameter and stationary outer cylinder were separated by $0.7 \mathrm{~mm}$ gap. All experiments were performed at temperature of $25^{\circ} \mathrm{C}$. Sample solutions showed Newtonian behaviour up to concentration of $32.5 \%$ above which pseudoplastic character was observed. Solutions viscosity at $5 \mathrm{~s}^{-1}$ (safely in Newtonian region) was selected for correlation with diameter of electrospun fibers.

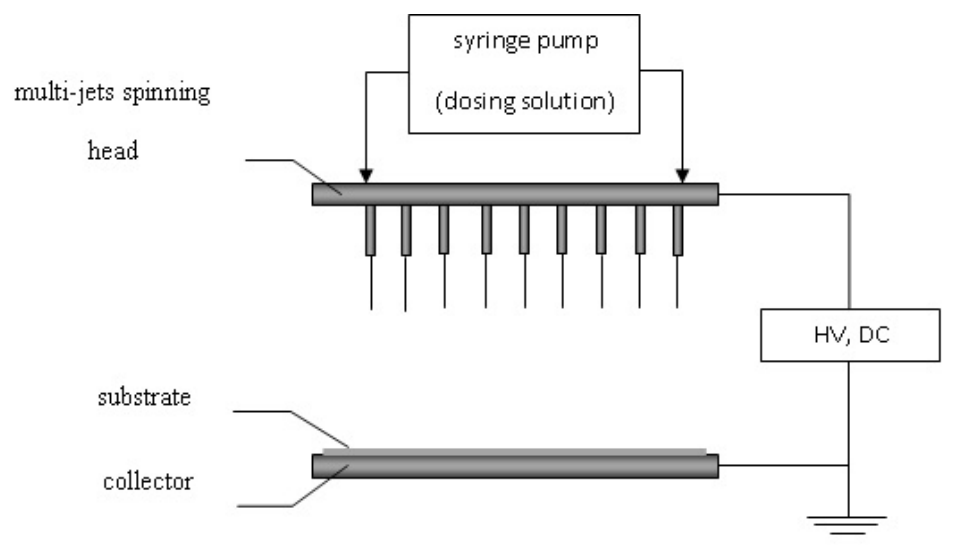

FIGURE 1. Schematic illustration of multi-jet electrospinning apparatus.

The schematic illustration of used electrospinning apparatus is presented in Figure 1. It is based on multi-jet principle when polymer solution is pumped into spinning head with parallel jets. The mass transfer from jet's tips to collector is caused by application of high voltage field. The character of product can by from nanobeads (electro-spraying) or submicron fibers (electro-spinning) to formation of polymer conglomerates. The deposited material is solidified from the state of solution to solid state by solvent evaporation which should mainly occur during spinning process.

The effects of solvent system and PVAc concentration onto electrospinning process are summarized in Tab.1. According that the process ran or not and the structure of the product differ from nano-beads and nano-fibers to production of PVAc conglomerates. 
TABLE 1. Characterization of electrospinning process for different composition of solvent system, acetic acid with water (AA: $\left.\mathrm{H}_{2} \mathrm{O}\right)$ and different concentration of dissolved PVAc.

\begin{tabular}{|c|c|c|}
\hline Solvent system & $\begin{array}{c}\text { PVAc wt. Concentration } \\
\text { [ wt. \%] }\end{array}$ & Process characterization \\
\hline \multirow[t]{2}{*}{ AA } & $5-40$ & without process, no mass transfer \\
\hline & $5-7$ & $\begin{array}{l}\text { electro-spraying, stable mass transfer, PVAc beds } \\
\text { with minimum of fibers }\end{array}$ \\
\hline \multirow[t]{3}{*}{ AA: $\mathrm{H}_{2} \mathrm{O}-3: 1$} & $8-32.5$ & $\begin{array}{l}\text { electro-spinning, stable mass transfer, PVAc fibe } \\
\text { creation of submicron size }\end{array}$ \\
\hline & $32.5-40$ & $\begin{array}{c}\text { unstable or no mass transfer, unstable PVAc fiber } \\
\text { formation of micron size }\end{array}$ \\
\hline & $5-8$ & $\begin{array}{l}\text { electro-spraying, stable mass transfer, PVAc beds } \\
\text { with minimum of fibers }\end{array}$ \\
\hline AA: $\mathrm{H}_{2} \mathrm{O}-1: 1$ & $9-30$ & $\begin{array}{l}\text { electro-spinning, stable mass transfer, PVAc fibe } \\
\text { creation of submicron size }\end{array}$ \\
\hline & $32.5-40$ & $\begin{array}{c}\text { unstable or no mass transfer, unstable PVAc fiber } \\
\text { formation of micron size }\end{array}$ \\
\hline $\mathrm{AA}: \mathrm{H}_{2} \mathrm{O}-1: 3$ & & PVAc not solved \\
\hline
\end{tabular}

The influence of solution concentartion onto produced fibers diamether is demonstrated by SEM analyses presented in Figure 2 and Figure 3. It represents examples of prepared PVAc non-woven mats for different PVAc concentrations and solvent system AA: $\mathrm{H}_{2} \mathrm{O}$ $(3: 1)$. It is clearly visible that the fibers diamether increase with solution concentration. Both concentration series based on mixture of $\mathrm{AA}: \mathrm{H}_{2} \mathrm{O}$ (3:1 and 1:1) poses good process-ability by electrospinning process. The fibers are created in very broad range of PVAc concentrations from approx. 8-9 wt. \% to $30 \mathrm{wt} \%$ of PVAc. On other hand electro-spraying below its lower limit or unstable process leading to PVAc micron size fiber and PVAc conglomerates above $30 \mathrm{wt}$. \% of PVAc were observed.
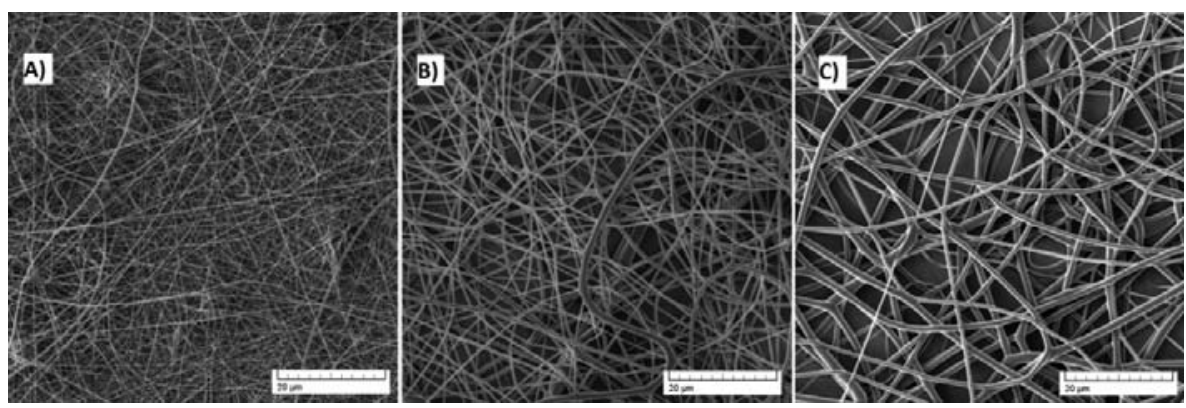

FIGURE 2. SEM images (at 3000x) of PVAc non-woven mats prepared by technology of electrospinning from mixture AA : $\mathrm{H}_{2} \mathrm{O}-3: 1(\mathrm{v} / \mathrm{v})$ with a) $10 \mathrm{wt}$. \% of PVAc - fiber main diameter $\left.89 \mathrm{~nm}, \mathrm{~b}\right) 20 \mathrm{wt}$. \% of PVAc - fiber main diameter $401 \mathrm{~nm}, \mathrm{c}) 30 \mathrm{wt}$. \% of PVAc - fiber main diameter $830 \mathrm{~nm}$. 


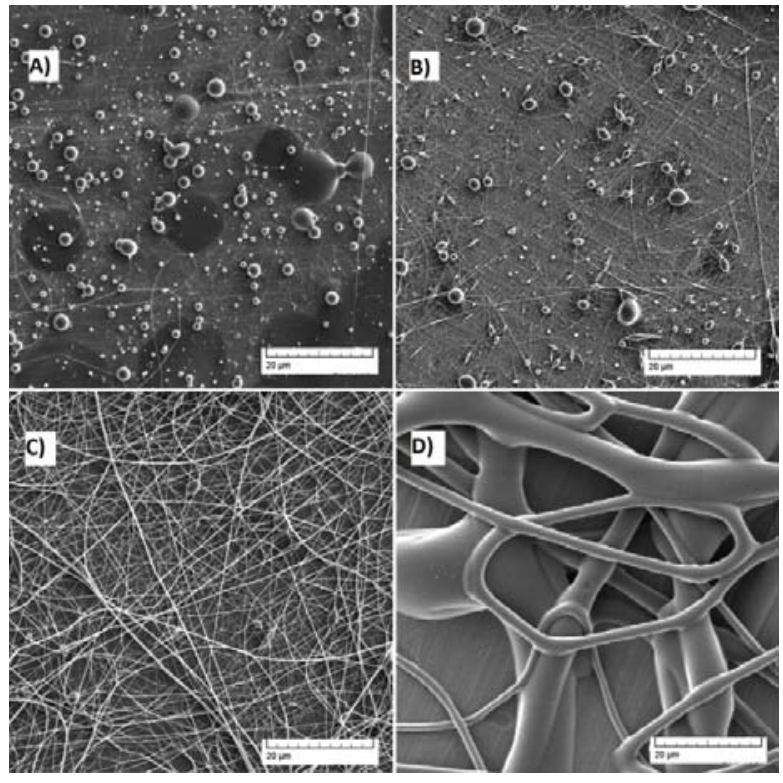

FIGURE 3. SEM images (at 3000x) of transition between electro-spraying and electro-spinning in solvent system AA : $\mathrm{H}_{2} \mathrm{O}-3: 1(\mathrm{v} / \mathrm{v})$ : a) 5 wt. \% of PVAc, b) 7 wt. $\%$ of PVAc c) 9 wt. $\%$ of PVAc and d) PVAc micron size fiber and PVAc conglomerates for 32.5 wt. \% of PVAc.

There were found significant differences in fibers diameters in the used concentration range. The fiber diameters differ by more than one order of magnitude. Table 2 presents an interval of fiber diameter between lower and upper PVAc concentrations.

TABLE 2. The main fiber diameter and viscosity of solutions.

\begin{tabular}{lcc}
\hline solution & $\begin{array}{c}\text { Fiber diameter } \\
\text { (nm) }\end{array}$ & $\begin{array}{c}\text { Viscosity } \\
\text { (Pa.s) }\end{array}$ \\
\hline AA: $\mathrm{H}_{2} \mathrm{O}(3: 1), 9$ wt. \% PVAC & $67 \pm 10$ & 0.066 \\
AA: $\mathrm{H}_{2} \mathrm{O}(3: 1), 32,5$ wt. \% PVAC & $1171 \pm 40$ & 7.720 \\
AA: $\mathrm{H}_{2} \mathrm{O}(1: 1), 9$ wt. \% PVAC & $62 \pm 10$ & 0.039 \\
AA: $\mathrm{H}_{2} \mathrm{O}(1: 1), 32,5$ wt. \% PVAC & $950 \pm 32$ & 6.655 \\
\hline
\end{tabular}

Next Figure 4 presents the dependence of viscosity on the concentration of PVAc solutions measured for both concentration series. It demonstrates that viscosity increase exponentially with solutions concentration. The dependences for both concentration series are nearly identical. The similar exponential character was found for the dependence of fiber mean diameter on concentration also presented in Figure 4. Slightly thicker fibers 
are created from AA: $\mathrm{H}_{2} \mathrm{O}-3: 1$ system. This fact is reflected in slightly lower viscosity of this solution, especially at PVAC concentrations higher than $15 \mathrm{wt} \%$.

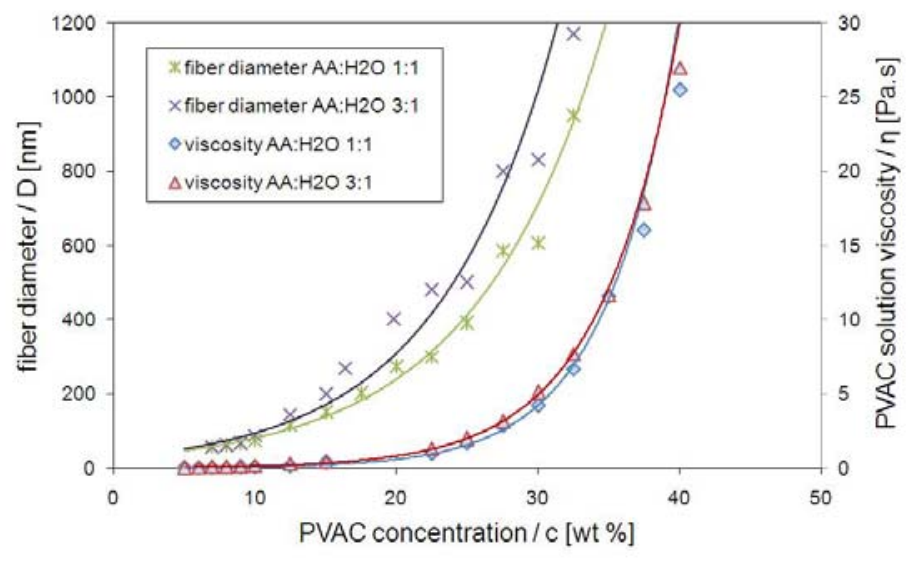

FIGURE 4. Dependence of mean diameter of nanofiber (D) and solutions viscosity ( $\eta$ ) on PVAC concentration (c) in solvent system AA : $\mathrm{H}_{2} \mathrm{O}-3: 1(\mathrm{v} / \mathrm{v})$ and $\mathrm{AA}: \mathrm{H}_{2} \mathrm{O}-1: 1(\mathrm{v} / \mathrm{v})$.

The influence to viscosity both solutions onto fiber diameter is presented in Figure 5. It seems that the influence of viscosity on fiber diameter is gradually decreasing. Difference between the curves of both types of solutions again increases with the increase of viscosity difference.

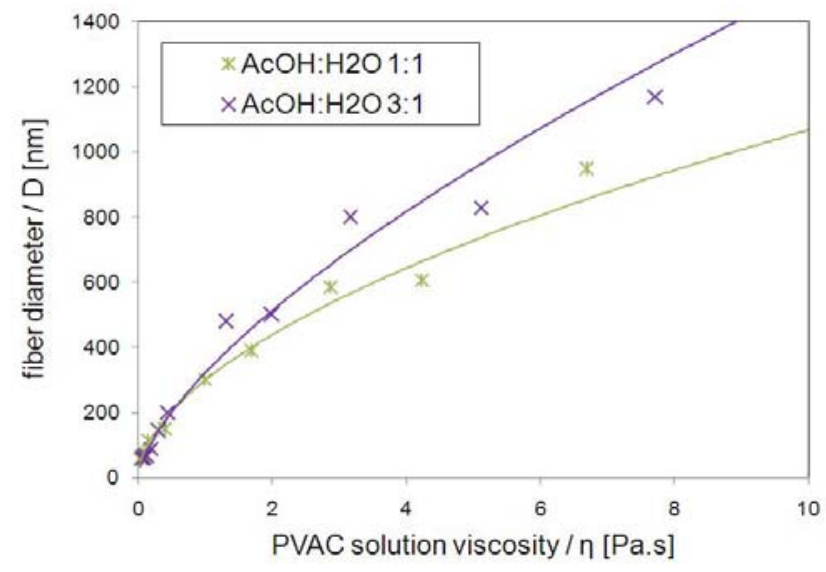

FIGURE 5. Dependence of fiber diameter (D) on PVAC solution viscosity $(\eta)$ in solvent system AA : $\mathrm{H}_{2} \mathrm{O}-3: 1(\mathrm{v} / \mathrm{v})$ and $\mathrm{AA}: \mathrm{H}_{2} \mathrm{O}-1: 1(\mathrm{v} / \mathrm{v})$. 
These dependencies are easy to describe a power function. Dependence of fiber diameter (D) on the viscosity $(\eta)$ of these solutions are follows: solution AA : $\mathrm{H}_{2} \mathrm{O}(3: 1)$ $\mathrm{D}(\mathrm{nm})=322,14 \cdot \eta\left(\right.$ Pa.s $^{0.6714}$ and It for solution based on mixture AA : $\mathrm{H}_{2} \mathrm{O}(1: 1)$ : $\mathrm{D}(\mathrm{nm})=299.14 \cdot \eta(\text { Pa.s })^{0.552}$.

\section{CONCLUSION}

The PVAc nanofibers with diameter from approximately $60 \mathrm{~nm}$ to $1000 \mathrm{~nm}$ were prepared by technology of electrospinning for acetic acid/water solvent system using by multi-jet apparatus. The fibers diameter was controlled by one simple parameter such as PVAc solution concentration/viscosity when increased viscosity leads to production of thicker fibers. It was found that optimal volume range of acetic acid and water is $3: 1$ and $1: 1(\mathrm{v} / \mathrm{v})$. The stable electrospinning process was found in PVAc concentration range from 8 to $30 \%(\mathrm{w} / \mathrm{v})$ for volume ration $3: 1$ and PVAC concentration range from 9 to $30 \%(\mathrm{w} / \mathrm{v})$ for volume ratio $1: 1$.

\section{ACKNOWLEDGMENTS}

This article was created with support of Operational Programme Research and Development for Innovations co-funded by the European Regional Development Fund (ERDF) and national budget of Czech Republic within the framework of the Centre of Polymer Systems project (reg.number: CZ.1.05/2.1.00/03.0111). Special thanks go to the SPUR a.s. (http://www.spur.cz/) for providing the multi-jet electrospinning laboratory device. This device was acquired with support of operational programme Ministry industry and trade: enterprise and innovation (Potential) co-funded by the european regional development fund and national budget of Czech republic within the framework of extension center for industrial research and development of commercial production of plastics (project number: 4.2PT02/017).

\section{REFERENCES}

1. I. D. Kim, A. Rothschild, B. H. Lee, D. Y. Kim, S. M. Jo, and H. L. Tuller, Nano Lett. 6, 2009-2013 (2006).

2. N. Dharmaraj, H. C. Park, C. K. Kim, H. Y. Kim' and D. R. Lee, Materials Chemistry and Physics 87, 5-9 (2004).

3. W. Ju, J. H. Park, H. R. Jung, S. J. Cho and W. J Lee, Composites Science and Technology 68, 1704-1709 (2008).

4. D. Li and Y. Xia, Nano Letters 3, 555-560 (2003).

5. S. Ramakrishna and K. Fujihara: An Introduction toElectrospinning and Nanofibers. World Scientific Publishing Ltd, Singapore (2005).

6. A. Greiner, J. H. Wendorff, Angew. Chem. Int. Ed. 46(30), 5670-5703 (2007).

7. L. Yarin. Electrospining of Nanofibers PolymerSolution and Melts. Institute of Fundamental Technological, Research Poland, Warsaw (2003). 
8. Abhay Moha: Formation and Characterization Electrospun Nonwovans Webs, Textile Management and Technology. Raleight University Press, North Carolina (2002).

9. D. Kimmer, P. Slobodian, D. Petras, M. Zatloukal, R. Olejnik, P. Saha, P. J. Appl. Polym. Sci. 111, 2711-2714 (2009).

10. C. Qizheng, D. Xiangting, Y. Weili, W. Jinxian, W. Huiru, Y. Xiaofeng, Y. Xiaohui X. J. C. Gongcheng, Rare Metal Materials and Engineering 35, 1167-1171 (2006).

11. P. Gupta, C. Elkins, T. E. Long, C. L. Wilkes, Polymer 46, $4799-4810$ (2005).

12. J. M. Deitzel, J. Kleinmeyer, D. Harris, N.C. B. Tan, Polymer 42, 261 - 272 (2001). 
Copyright of AIP Conference Proceedings is the property of American Institute of Physics and its content may not be copied or emailed to multiple sites or posted to a listserv without the copyright holder's express written permission. However, users may print, download, or email articles for individual use. 